\title{
Cerebral Venous Thrombosis Associated with COVID-19
}

\author{
(DD.D. Cavalcanti, (DE. Raz, (D) M. Shapiro, (D). Dehkharghani, (D). Yaghi, (D). Lillemoe, (DE. Nossek, (D). Torres, (D). Jain, \\ (D) H.A. Riina, (D) A. Radmanesh, and (DP.K. Nelson
}

\begin{abstract}
SUMMARY: Despite the severity of coronavirus disease 2019 (COVID-19) being more frequently related to acute respiratory distress syndrome and acute cardiac and renal injuries, thromboembolic events have been increasingly reported. We report a unique series of young patients with COVID-19 presenting with cerebral venous system thrombosis. Three patients younger than 41 years of age with confirmed Severe Acute Respiratory Syndrome coronavirus 2 (SARS-Cov-2) infection had neurologic findings related to cerebral venous thrombosis. They were admitted during the short period of 10 days between March and April 2020 and were managed in an academic institution in a large city. One patient had thrombosis in both the superficial and deep systems; another had involvement of the straight sinus, vein of Galen, and internal cerebral veins; and a third patient had thrombosis of the deep medullary veins. Two patients presented with hemorrhagic venous infarcts. The median time from COVID-19 symptoms to a thrombotic event was 7 days (range, 2-7 days). One patient was diagnosed with new-onset diabetic ketoacidosis, and another one used oral contraceptive pills. Two patients were managed with both hydroxychloroquine and azithromycin; one was treated with lopinavirritonavir. All patients had a fatal outcome. Severe and potentially fatal deep cerebral thrombosis may complicate the initial clinical presentation of COVID-19. We urge awareness of this atypical manifestation.
\end{abstract}

ABBREVIATIONS: COVID-19 = coronavirus disease 2019; CVT = cerebral venous thrombosis; RT-PCR = real-time reverse transcriptase polymerase chain reaction; SARS-CoV2 = Severe Acute Respiratory Syndrome-coronavirus 2

A novel Severe Acute Respiratory Syndrome-coronavirus 2 (SARS-CoV2) was identified on January 7, 2020, by the Chinese Center for Disease Control and Prevention from a nasopharyngeal swab in a patient with atypical pneumonia in Wuhan, Hubei province, China. ${ }^{1}$ The mortality rate of critically ill patients with COVID-19 is high. As of May 13, 2020, more than 1.4 million individuals had tested positive for the SARS-CoV2 in the United States, leading to $>84,000$ deaths. Acute cardiac injury, acute kidney injury, and precipitous thromboembolic events have been increasingly reported and may develop irrespective of pulmonary or respiratory symptoms at presentation. ${ }^{1-5}$

Recent studies have reported the potential development of a hypercoagulable state in COVID-19.,3,6,7 Viral infections may promote dysfunction of endothelial cells, leading to excess thrombin

Received May 1, 2020; accepted after revision May 14.

From the Departments of Radiology (D.D.C., E.R., M.S., S.D., R.J., A.R., P.K.N.),

Neurology (S.Y., K.L., J.T.), and Neurosurgery (E.N., H.A.R.), NYU Grossman School of Medicine, New York, New York.

Please address correspondence to Eytan Raz, MD, PhD, Bernard and Irene Schwartz Neurointerventional Radiology Section, Department of Radiology, NYU Langone Health, 550 1st Ave, New York, NY; e-mail: eytan.raz@gmail.com

-- Indicates open access to non-subscribers at www.ajnr.org

http://dx.doi.org/10.3174/ajnr.A6644

generation and inhibition of fibrinolysis. ${ }^{8-10}$ Moreover, hypoxemia is associated with an elevation of blood viscosity and activation of hypoxia-related genes that mediate coagulation and fibrinolysis, favoring thrombotic events. ${ }^{11,12}$ This septic-like coagulopathy additionally may lead to venous thrombosis, pulmonary embolism, and ultimately disseminated intravascular coagulation. ${ }^{3,4}$ Cerebral venous thrombosis, in particular, can present with a broad variety of neurologic signs and symptoms. ${ }^{13,14}$ We report herein 3 independent cases of patients with COVID-19 who presented with stroke due to cerebral venous thrombosis and had uniformly fatal outcomes.

\section{MATERIALS AND METHODS}

We report 3 independent cases of patients presenting to a single academic hospital system in the initial weeks of the COVID-19 surge during a 10-day period. The 3 patients composing our initial experience developed profound neurologic injury secondary to cerebral venous thrombosis (CVT), with SARS-CoV-2 infection confirmed by real-time reverse transcriptase polymerase chain reaction (RT-PCR) assay. The mean age was 34 years (range, 23-41 years; 2 men and 1 woman). All patients presented during 10 days beginning in March 2020. The study was approved by the institutional review board. Medical charts were 


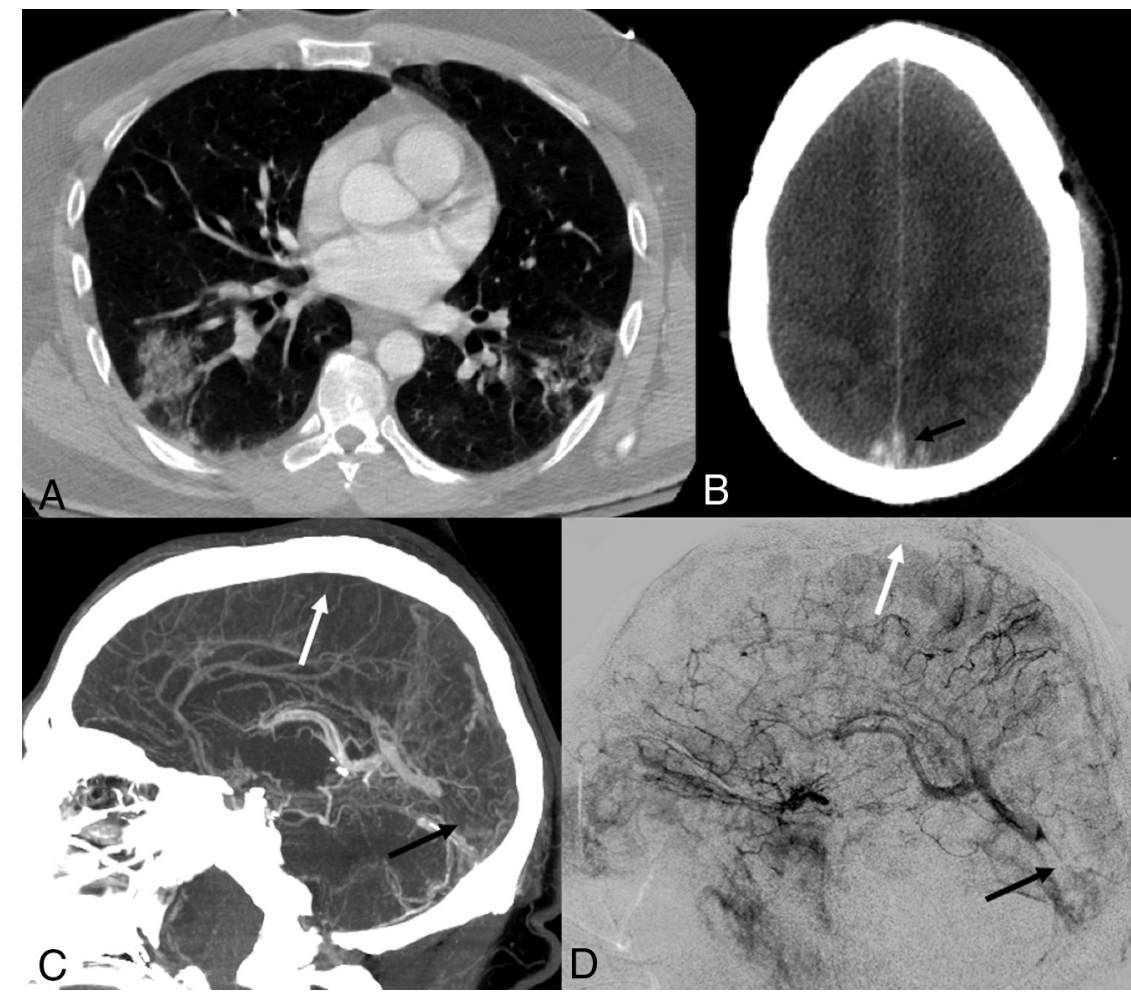

FIG 1. Acute onset of cerebral venous thrombosis in multiple locations in a man with COVID-19 without any significant comorbidities except for mild autism spectrum disorder and Tourette syndrome. A, Axial view of a CT of the chest shows patchy multifocal peripheral and peribronchovascular airspace opacities with a combination of ground-glass and consolidation in different lobes. B, Axial view, CT of the head without contrast, shows effacement of the cerebral sulci suggestive of significant cerebral edema; hyperdensity is seen in the region of the superior sagittal sinus posteriorly (arrow), characteristic of dural venous thrombosis. C, CVT with sagittal reconstruction demonstrates extensive occlusive filling thrombus within the superior sagittal (white arrow), right transverse, and sigmoid sinuses; thrombosis extends from the torcula into the straight sinus (black arrow). There is occlusion of several cortical veins adjacent to the superior sagittal sinus as well. $D$, Digital subtraction angiography, lateral view, reveals significant venous congestion involving the entire right cerebral hemisphere with no visualization of the superior sagittal (white arrow), transverse, and sigmoid sinuses, with clot extension in the straight sinus (black arrow).

reviewed for significant history, physical examination findings, laboratory findings, and imaging. Due to the retrospective nature of this report, informed consent was not required. We used the Case Report Guideline (CARE; https://www.care-statement.org/) checklist when writing this report. ${ }^{15}$

\section{RESULTS}

\section{Case 1}

A 38-year-old man with mild autism spectrum disorder was admitted to the emergency department with vomiting and diarrhea for 10 days, headache for the past 7 days, and altered mental status for the past 2 days. At presentation, he exhibited signs of dehydration, blood pressure of $127 / 62 \mathrm{~mm} \mathrm{Hg}$, and temperature of $102.9^{\circ} \mathrm{F}$. He was screened by nasopharyngeal swab with an RT-PCR for SARS-CoV-2, with positive findings. Chest radiograph and CT confirmed patchy multifocal peripheral and peribronchovascular air space opacities (a combination of groundglass and consolidation) in all lobes (Fig $1 A$ ).
Head CT revealed hyperdensity in the straight sinus, distal superior sagittal sinus, torcular, and right transverse sinus, as well as in several cortical veins adjacent to the superior sagittal sinus, a pattern consistent with CVT (Fig 1B). There was associated cerebral edema. Pertinent laboratory results are listed in the Table. CT venography confirmed CVT, including a nearocclusive thrombus in the right internal cerebral vein (Fig 1C). Enoxaparin, $70 \mathrm{mg}$, was given subcutaneously twice a day. Nevertheless, the patient rapidly decompensated, with extensor posturing of the arms and clonus. Cranial nerve examination findings were normal; the NIHSS score was 14 . The patient's temperature increased to $104.3^{\circ} \mathrm{F}$, his respiratory rate increased to 40 breaths per minute, and he quickly became hypoxemic, gasping for air, and was intubated 7 hours after admission.

The patient was subsequently taken to the angiography suite for a percutaneous venous mechanical thrombectomy. Arterial injections showed decreased contrast transit time throughout the brain parenchyma, indirectly suggesting significantly increased supra- and infratentorial pressures (Fig 1D). Marked venous congestion of the right hemisphere, with similar-but-lesser involvement on the left due to partial patency of the sigmoid sinus and the associated vein of Labbé, and congestion of the vein of Galen, internal cerebral system, and posterior fossa were present.

Thrombectomy was performed using our standard procedures with satisfactory results in the superficial venous system (Fig $2 A-2 C$ ) but residual cortical vein thrombi as shown in Fig $2 D$. A microcatheter was left in the superior sagittal sinus with an infusion rate of $2 \mathrm{mg} / \mathrm{h}$ of tPA. No neurosurgical intervention was advised at that point. The patient was treated with lopinavir-ritonavir and had an initial improvement on neurologic examination in the following 6 hours; however, his respiratory status soon deteriorated, leading to cardiac arrest and death 32 hours after admission.

\section{Case 2}

An otherwise healthy 41-year-old woman, recently discharged from an outside hospital following a short and uneventful admission for COVID-19, presented to our emergency department with confusion and a sudden episode of aphasia. She had received hydroxychloroquine and azithromycin, started during her first 
Summary of laboratory findings at admission

\begin{tabular}{lccc}
\multicolumn{1}{c}{ Laboratory Findings } & Case 1 & Case 2 & Case 3 \\
\hline White cell count (per $\mathrm{mm}^{3}$ ) & 16,710 & 9950 & 8840 \\
Total neutrophils (per $\mathrm{mm}^{3}$ ) & 14,280 & 8390 & 6980 \\
Total lymphocytes (per $\mathrm{mm}^{3}$ ) & 490 & 940 & 1360 \\
Total monocytes (per $\mathrm{mm}^{3}$ ) & 1690 & 360 & 330 \\
Hemoglobin level (g/dL) & 14.3 & 10.4 & 12.3 \\
Platelet count (per $\mathrm{mm}^{3}$ ) & 141,000 & 239,000 & 86,000 \\
Activated partial thromboplastin time (sec) & 30.6 & 27.7 & 53.5 \\
Prothrombin time (sec) & 22.5 & 11.8 & 19.1 \\
INR & 1.9 & 0.99 & 1.6 \\
D-dimer level (ng/mL) & 55,000 & 787 & 920 \\
Fibrinogen level (mg/dL) & 121 & - & - \\
Albumin level (g/dL) & 4.4 & 4.4 & 4.7 \\
Alanine aminotransferase results (U/L) & 27 & 27 & 19 \\
Aspartate aminotransferase levels (U/L) & 31 & 26 & 38 \\
\hline
\end{tabular}

Note:-INR indicates international normalized ratio; -, not available.

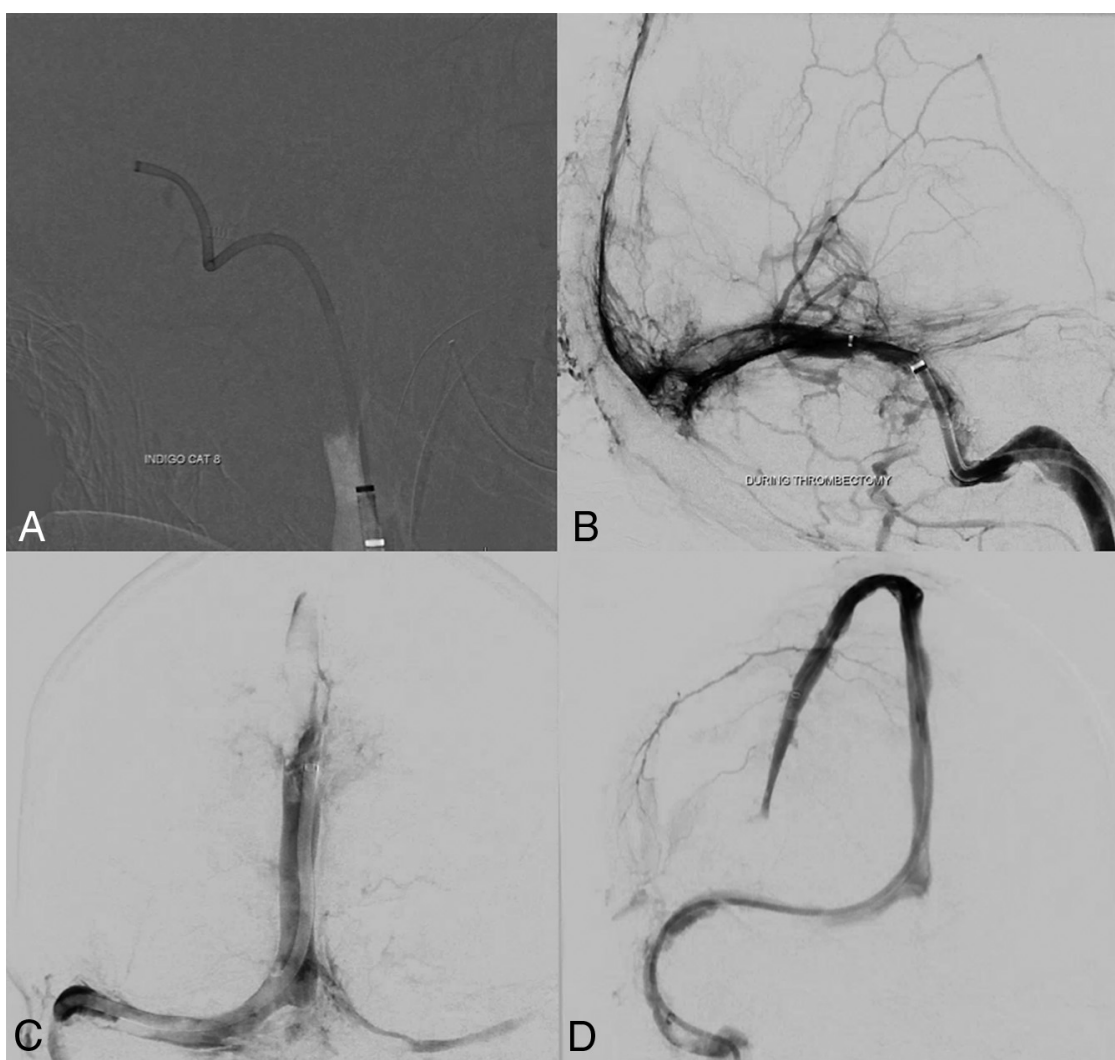

FIG 2. Images acquired during the intervention in case 1. A, A 12F Flexor Shuttle Guiding Sheath (Cook) was brought to the internal jugular vein. An $8 \mathrm{~F}$ Indigo Aspiration Catheter (Penumbra) is seen in the right transverse-sigmoid junction after thrombectomy of the right sigmoid sinus. $B$, Multiple control angiograms and venograms were obtained during the venous thrombectomy; it is possible to see a significant amount of thrombus partially occluding the torcula and the distal two-thirds of the right transverse sinus. Partial recanalization of the posterior third of the superior sagittal sinus is also seen. C, Venography, cranial view, anterior-posterior projection, shows complete recanalization of the torcula, and most of the posterior third of the superior sagittal sinus. $D$, Venography, cranial view, right anterior oblique projection reveals full recanalization of the superior sagittal sinus. A microcatheter was left in its anterior third to maintain continuous tPA infusion.

admission. Home medications included estrogen-containing oral contraceptives. Her blood pressure was $107 / 75 \mathrm{~mm} \mathrm{Hg}$, and she was afebrile. The patient had global aphasia and left-gaze preference with an NIHSS score of 16. Initial head CT findings were normal. Intravenous tPA was not given because last her known well time was $>4.5$ hours. CT angiography did not identify any large-vessel occlusion. There was right-greater than-left multifocal consolidation throughout the lungs on chest imaging.

While waiting for a brain MR imaging, she developed labored breathing, a further decrease in the level of consciousness, and worsened neurologic examination findings with extensor posturing to noxious stimulation; she was then intubated and sedated. The CSF analysis revealed elevated protein levels $(616 \mathrm{mg} / \mathrm{dL}), 41$ white blood cells $/ \mathrm{mm}^{3}$ with polymorphonuclear predominance (84\%), and a normal glucose level. A multiplex PCR assay was negative for common pathogens causing meningitis and encephalitis. A repeat head CT showed interval development of a venous infarction in the left basal ganglia, thalamus, and mesial temporal lobe with hemorrhagic transformation, intraventricular hemorrhage, and obstructive hydrocephalus (Fig 3A, $-B$ ). A chest CT was characteristic for COVID-19 (Fig 3C). A CT venogram confirmed occlusion of the internal cerebral veins with significantly reduced enhancement of the vein of Galen and distal straight sinus (Fig 3D). Concomitantly, her D-dimer level increased from 787 to $2032 \mathrm{ng} /$ $\mathrm{mL}$; it had been $243 \mathrm{ng} / \mathrm{mL} 7$ days prior. An external ventricular drain was placed. Heparin infusion was initiated without a bolus in the treatment of deep CVT. The patient soon exhibited loss of brain stem reflexes and died 4 days from presentation.

\section{Case 3}

A 23-year-old man with no known medical history presented with lethargy in the setting of 1 week of headaches, body aches, fever, and dry cough. Blood pressure at presentation was $95 / 53 \mathrm{~mm} \mathrm{Hg}$. Multifocal pneumonia was present on the initial chest $\mathrm{x}$-ray. RT-PCR was positive for SARS-CoV-2. A head CT was ordered due to the decreased level of consciousness and revealed patchy areas of low density in the bilateral cerebral hemispheres with foci of subcortical hemorrhage in the left parieto-occipital region. A 


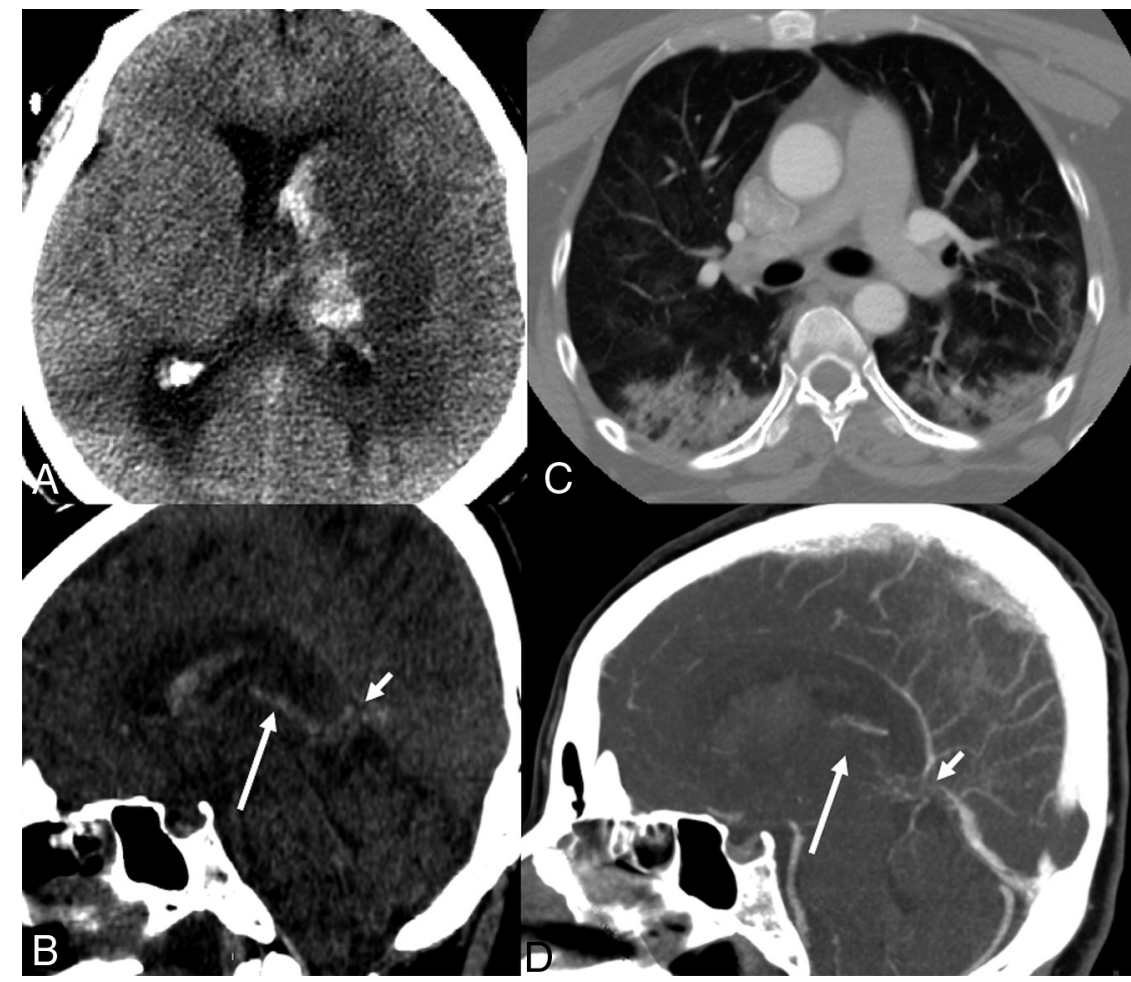

FIG 3. Subacute onset of isolated deep cerebral venous thrombosis in a patient with COVID-19. $A$, Noncontrast head $C T$, axial view, reveals an infarct of the left basal ganglia and thalamus, with hemorrhagic transformation and intraventricular hemorrhage with obstructive hydrocephalus. $B$, Noncontrast head CT, sagittal reconstruction, reveals hyperdensity in the topography of the vein of Galen (short arrow) and left internal cerebral vein (long arrow), corresponding to deep venous thrombosis. C, CT of the chest, axial view, demonstrates patchy multifocal airspace opacities combining ground-glass and consolidation in different lobes, suggestive of pneumonia/pneumonitis. D, CT venogram, MPR sagittal reconstruction, shows a filling defect in the vein of Galen (short arrow), internal cerebral veins (long arrow), and the anterior aspect of the inferior sagittal sinus, confirming deep venous thrombosis.

CTA of the head had negative findings; however, there remained concern for CVT. The initial laboratory work-up further established a new diagnosis of diabetic ketoacidosis with new-onset diabetes mellitus (glucose level $=1384 \mathrm{mg} / \mathrm{dL}$ and $\mathrm{pH}=7.0$ ). Azithromycin and hydroxychloroquine were both administered.

A subsequent brain MR imaging (Fig 4) revealed confluent, nonenhancing regions of pathologically reduced diffusion throughout the subcortical and deep hemispheric white matter bilaterally, left greater than right. Punctate foci of susceptibility artifacts consistent with petechial hemorrhage were revealed on gradient recalled-echo images. Differential considerations included potential complications of diabetic ketoacidosis, which can include arterial and venous compromise together with secondary injury by increased intracranial pressure, and posterior reversible encephalopathy syndrome-like white matter injury. The imaging pattern and absence of large-vessel occlusion disfavored the diagnosis of atheroembolic infarctions or deep MCA borderline ischemia. Acute necrotizing leukoencephalitis was considered unlikely in the absence of deep ganglia injury, and toxic-metabolic etiologies were unsupported by the history. In combination with generalized low intensity of the white matter on long-echo T2- and T2*-weighted images, the imaging appearance was thought to be consistent with manifestations of a generalized vaso-occlusive crisis such as can occur in disseminated intravascular coagulation, thrombotic thrombocytopenic purpura, and related thrombotic microangiopathies, including compromise of the deep medullary veins. ${ }^{16,17}$ Common to the preceding processes is endothelial dysfunction and impaired thromboresistance, which have been reported extensively in COVID-19 and other SARS-mediated disorders. ${ }^{18}$

In the ensuing days, the patient further deteriorated, with D-dimer levels increasing from earlier values of $1625 \mathrm{ng} / \mathrm{mL}$ to $>11,000 \mathrm{ng} / \mathrm{mL}$ the day he died and ferritin values reaching $18,431 \mathrm{ng} / \mathrm{mL}$. The patient was intubated following worsening hypotension and fulminant acute respiratory distress syndrome in the following days before his death.

\section{DISCUSSION}

We report an unusual presentation characterized by catastrophic cerebral venous thrombosis in young, previously healthy patients, infected with SARS CoV 2, previously healthy and potentially without antecedent cardiopulmonary symptoms or fever. Although dehydration was a precipitating factor in cases 1 and 3, and, oral contraceptives, a risk factor in case 2, COVID-19 was probably an additive risk factor in this series.

CVT is a rare cause of stroke, accounting for approximately $0.5 \%$ of all stroke cases, ${ }^{19,20}$ and associated with a reported mortality of $4 \% .{ }^{13}$ Interestingly the first report of thrombosis involving the superior sagittal sinus and lateral sinuses from 1825 led to a long-standing belief of a direct relationship with infections. ${ }^{21,22}$ Indeed, Krayenbühl ${ }^{23}$ demonstrated, in 1968 , that $40 \%$ of a series of 92 patients with CVT were associated with infection. Central nervous system infections per se are both: a risk factor for CVT, and, are associated with a poor prognosis. ${ }^{24}$ Moreover, in a recent series, a pro-coagulopathic state could be identified in as many as $48 \%$ of patients with $\mathrm{CVT}^{20}$

The superior sagittal sinus is the more frequently reported cerebral venous structure involved (63\% of patients in a large MR imaging series); however, more extensive multi-site thrombosis is the typical finding. The deep venous system is an independent predictor of death in the International Study on Cerebral Vein and Dural Sinus Thrombosis (odds ratio, 8.5; 95\% confidence interval, 2.6-27.8). ${ }^{13,14}$ Most reports included children, especially neonates.

\section{Hypercoagulable State in Other Scenarios}

Numerous factors are related to CVT, including the use of oral contraceptives, pregnancy, and puerperium, which produce 


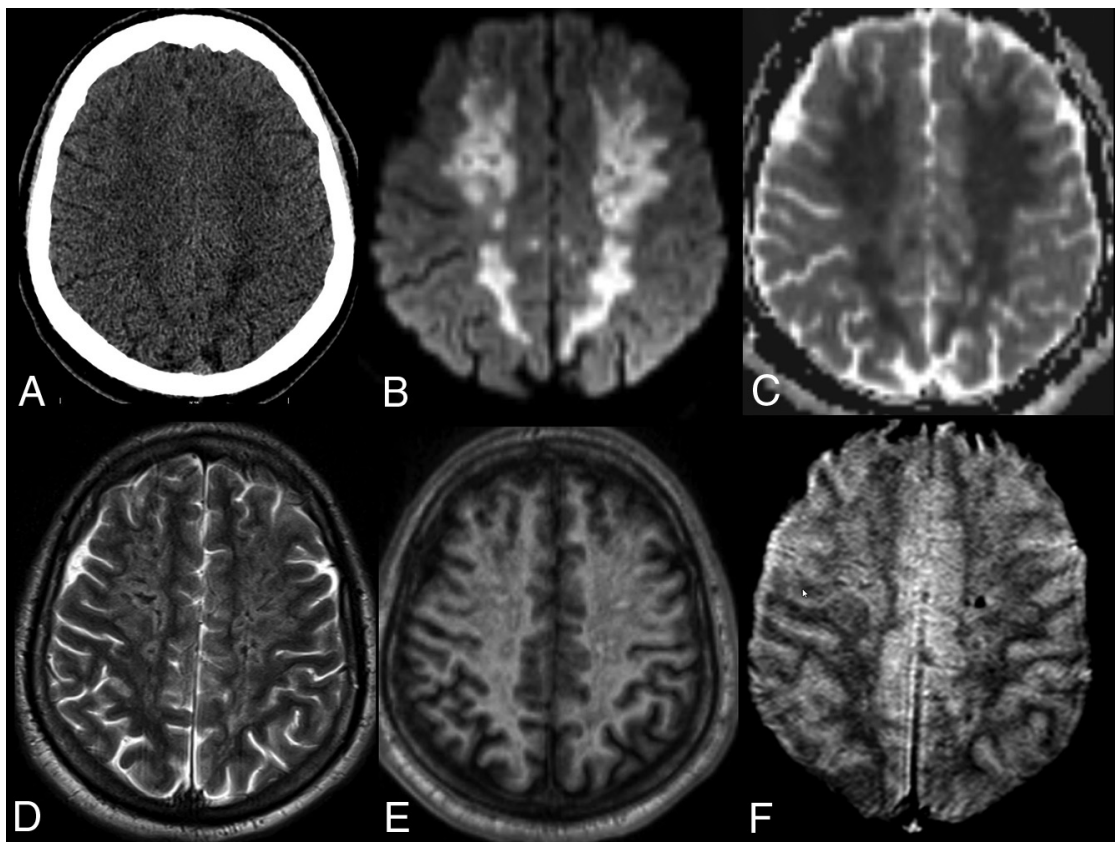

FIG 4. A 28-year-old man presenting with a decreased level of consciousness. Imaging included CT of the head (A), and MR imaging with DWI (B), ADC maps (C), T2WI (D), TIWI without contrast $(E)$ and $2 D T 2^{*}$ gradient recalled-echo $(F)$. Confluent areas of low density are present in the bilateral cerebral hemispheres in $A$, corresponding to nonenhancing, pathologically reduced diffusion on $B$ and $C$. T2- and $T 2^{*}$-weighted images reveal generalized low intensity of the white matter in excess of that explained by subtle foci of petechial hemorrhage in $F$ and consistent with slow or impaired outflow of the deep medullary venous system.

transient prothrombotic states. ${ }^{19,25}$ CVT accounts for $2 \%$ of pregnancy-associated strokes. $^{26}$ Diabetes mellitus, systemic inflammatory disease, cancer, hematologic disorders, head and neck infections, and CNS infections and hyperhomocysteinemia are other significant causes, and the patients were not systematically worked up for all those conditions. ${ }^{11,12,27,28}$ Anemia is another known risk factor for CVT, though not present in our patients. $^{29}$

Numerous viral infections are associated with coagulopathy. ${ }^{8-10,30-32}$ Direct or indirect activation of endothelial cells by viruses may impair coagulation and the fibrinolytic systems. Moreover, antiphospholipid antibodies can be identified in several viral infections, including cytomegalovirus, HIV, and varicella zoster virus, ${ }^{8-10}$ also in immunocompetent patients. ${ }^{9}$ A hypercoagulable state is well-known among patients with human herpes viruses (DNA viruses) and HIV. ${ }^{8-10,30,32}$ Chronic HIV infection has been associated with up to a 10 -fold increased risk of venous thrombosis. ${ }^{8}$

Finally, microvascular thrombosis was seen in a specific transgenic mouse model, used in studying the Middle East respiratory syndrome coronavirus infection. ${ }^{31}$

\section{Hypercoagulable State in COVID-19}

A recent study comparing a cohort of 94 patients with SARSCoV-2 infection in a hospital in Wuhan with 40 healthy volunteers found values of D-dimer, fibrin/fibrinogen-degradation products, and fibrinogen to be significantly higher among patients with COVID-19. ${ }^{6}$
In reporting a $21.6 \%$ incidence of deep venous thrombosis in 88 laboratory-confirmed cases in Wuhan, ${ }^{33}$ Wang et $\mathrm{al}^{3}$ observed positive correlations between the degree of $\mathrm{D}$-dimer elevation and the incidence of deep venous thrombosis with the severity of disease, possibly related to overwhelming endothelial cell activation. ${ }^{3,34}$ Indeed, D-dimer levels were $>500 \mathrm{ng} / \mathrm{mL}$ in all patients in this report at diagnosis, being $>55,000$ $\mathrm{ng} / \mathrm{mL}$ in case 1 .

There is also a growing understanding that antiphospholipid antibodies (anticardiolipin immunoglobulin A, and anti- $\beta 2$-glycoprotein I immunoglobulin A and immunoglobulin $G$ ) may play a role in both arterial and venous infarcts. Zhang et $\mathrm{al}^{7}$ found positive antiphospholipid antibodies in 3 patients with critical COVID-19 and multifocal ischemic strokes.

Yang et $\mathrm{al}^{34}$ reported a high prevalence of hypertension, diabetes, and respiratory system disease in a metaanalysis including 46,248 patients with severe presentation of COVID-19, some with well-known risk factors for venous thromboembolism. ${ }^{35}$ Moreover, increased immobility of vulnerable and at-risk patients may occur during resource-strained pandemics, with shortages of health care personnel further contributing to conditions of venous stasis and thromboembolism. ${ }^{12}$ More studies are needed to clarify the direct relationship of the SARS-CoV-2 and thromboembolic disease.

\section{Cerebrovascular Disease in Patients with COVID-19}

Recently, Li et $\mathrm{al}^{2}$ identified 13 patients (5.9\%) with stroke among 221 consecutive patients with confirmed SARS-CoV-2 infection in Wuhan. Among this cohort, 11 had severe disease while only one, a 32-year-old man, had CVT involving multiple cortical veins. Parenthetically, a surge in large-vessel arterial occlusive strokes was reported in a group of patients younger than 50 years of age in New York City. ${ }^{36}$

In general, approximately $80 \%$ of patients with CVT experience acute-to-subacute onset of symptoms. ${ }^{13}$ The median time from onset to diagnosis of the thrombotic events was 7 days, the same as reported in the literature. Although headache is the most commonly reported initial symptom; altered consciousness was the critical symptom in each of the present cases. When a patient is admitted to the hospital with headache, altered mental status, focal neurologic deficits, and seizures, the likelihood of an earlier diagnosis is higher. ${ }^{13}$ Early identification is critical because prompt anticoagulation and/ or endovascular management may decrease the progression of cerebral edema, intracranial pressure, and hemorrhage rates, improving outcomes. 


\section{Limitations}

The main limitation is that this is a small case series of only 3 patients collected in a short time. Also, 2 patients were treated with azithromycin and hydroxychloroquine before their CVTs, and the effects of these drugs during COVID-19 infection are under study and inconclusive at this time. Both may affect coagulation and interact with other medications and treatment, and it is unknown whether they could have been contributors to the CVTs. Moreover, there were concomitant signs of dehydration in the first case, and the second patient was on oral contraceptive pills, both known precipitating or risk factors for CVT. Another limitation of this work is the lack of a strongly confirmed diagnosis on case 3 .

\section{CONCLUSIONS}

An unusual presentation with catastrophic cerebral venous thrombosis in previously healthy young patients infected with SARS-CoV-2 was demonstrated. No conclusions can be drawn other than that these cases provide hints as to the accumulating evidence that COVID-19 is a serious contributor to hypercoagulation, increasing the fatality of the disease. Heightened awareness of this atypical but potentially treatable complication of the COVID-19 disease spectrum is encouraged.

Disclosures: Eytan Raz-UNRELATED: Expert Testimony: various law firms; Royalties: Springer; Travel/Accommodations/Meeting Expenses Unrelated to Activities Listed: MicroVention. Seena Dehkharghani-UNRELATED: Grants/ Grants Pending: anonymous donor, Comments: the grant paid to the institution by an anonymous donor administered through Open Impact, San Mateo, California*; Travel/Accommodations/Meeting Expenses Unrelated to Activities Listed: IschemaView, Comments: modest travel and research support. Rajan JainUNRELATED: Consultancy: Cancer Panels; Royalties: Thieme. Alireza RadmaneshUNRELATED: Stock/Stock Options: various stocks in retirement accounts unrelated to this work. *Money paid to the institution.

\section{REFERENCES}

1. Chen N, Zhou M, Dong X, et al. Epidemiological and clinical characteristics of 99 cases of 2019 novel coronavirus pneumonia in Wuhan, China: a descriptive study. Lancet 2020;395:507-13 CrossRef Medline

2. Li Y, Wang M, Zhou Y, et al. Acute cerebrovascular disease following COVID-19: a single center, retrospective, observational study. SSRN Electronic Journal January 2020. https://www.researchgate.net/ publication/340154622_Acute_Cerebrovascular_Disease_Following COVID-19_A_Single_Center_Retrospective_Observational_Study. Accessed April 13, 2020

3. Wang W, Sun Q, Bao Y, et al. Analysis of risk factors for the thromboembolic events from 88 patients with COVID-19 pneumonia in Wuhan, China: a retrospective report. Lancet 2020 April 6. https:// papers.ssrn.com/sol3/papers.cfm?abstract_id=3559633. Accessed April 13, 2020

4. Xie Y, Wang X. COVID-19 complicated by acute pulmonary embolism. Images in Cardiothoracic Imaging March 16, 2020. https://pubs. rsna.org/doi/10.1148/ryct.2020200067. Accessed April 11, 2020

5. Tang N, Li D, Wang X, et al. Abnormal coagulation parameters are associated with poor prognosis in patients with novel coronavirus pneumonia. J Thromb Haemost 2020;18:844-47 CrossRef Medline

6. Han H, Yang L, Liu R, et al. Prominent changes in blood coagulation of patients with SARS-CoV-2 infection. Clin Chem Lab Med 2020 March 16. [Epub ahead of Print] CrossRef Medline

7. Zhang Y, Xiao M, Zhang S, et al. Coagulopathy and antiphospholipid antibodies in patients with Covid-19. N Engl J Med 2020;382: e38 CrossRef Medline
8. Bibas M, Biava G, Antinori A. HIV-associated venous thromboembolism. Mediterr J Hematol Infect Dis 2011;3:e2011030 CrossRef Medline

9. Squizzato A, Gerdes VE, Buller HR. Effects of human cytomegalovirus infection on the coagulation system. Thromb Haemost 2005;93: 403-10 CrossRef Medline

10. Uthman IW, Gharavi AE. Viral infections and antiphospholipid antibodies. Semin Arthritis Rheum 2002;31:256-63 CrossRef Medline

11. Gupta N, Zhao YY, Evans CE. The stimulation of thrombosis by hypoxia. Thromb Res 2019;181:77-83 CrossRef Medline

12. Ortel TL. Acquired thrombotic risk factors in the critical care setting. Crit Care Med 2010;38:S43-50 CrossRef Medline

13. Canhao P, Ferro JM, Lindgren AG, et al; ISCVT Investigators. Causes and predictors of death in cerebral venous thrombosis. Stroke 2005;36:1720-25 CrossRef Medline

14. Girot M, Ferro JM, Canhao P, et al; ISCVT Investigators. Predictors of outcome in patients with cerebral venous thrombosis and intracerebral hemorrhage. Stroke 2007;38:337-42 CrossRef Medline

15. Gagnier JJ, Kienle G, Altman DG, et al; CARE Group. The CARE guidelines: consensus-based clinical case reporting guideline development. Glob Adv Health Med 2013;2:38-43 CrossRef Medline

16. Arrigoni F, Parazzini C, Righini A, et al. Deep medullary vein involvement in neonates with brain damage: an MR imaging study. AJNR Am J Neuroradiol 2011;32:2030-36 CrossRef Medline

17. Ellchuk TN, Shah LM, Hewlett RH, et al. Suspicious neuroimaging pattern of thrombotic microangiopathy. AJNR Am J Neuroradiol 2011;32:734-38 CrossRef Medline

18. Giannis D, Ziogas IA, Gianni P. Coagulation disorders in coronavirus infected patients: COVID-19, SARS-CoV-1, MERS-CoV and lessons from the past. J Clin Virol 2020;127:104362 CrossRef Medline

19. Saposnik G, Barinagarrementeria F, Brown RD Jr, et al; American Heart Association Stroke Council and the Council on Epidemiology and Prevention. Diagnosis and management of cerebral venous thrombosis: a statement for healthcare professionals from the American Heart Association/American Stroke Association. Stroke 2011;42:1158-92 CrossRef Medline

20. Devasagayam S, Wyatt B, Leyden J, et al. Cerebral venous sinus thrombosis incidence is higher than previously thought: a retrospective population-based study. Stroke 2016;47:2180-82 CrossRef Medline

21. Ribes M. Des recherches faites sur la phlébite. In: Académie Royale de Médecine. Revue Médicale Française et Etrangère et Journal de Clinique de l'Hôtel-Dieu et de la Charité de Paris 1825. 2018;3:5-41

22. Zuurbier SM, Coutinho JM, Stam J, et al; ISCVT Investigators. Clinical outcome of anticoagulant treatment in head or neck infection-associated cerebral venous thrombosis. Stroke 2016;47:127177 CrossRef Medline

23. Krayenbuhl HA. Cerebral venous and sinus thrombosis. Neurol Med Chir (Tokyo) 1968;10:1-24 CrossRef Medline

24. Ferro JM, Canhao P, Stam J, et al; ISCVT Investigators. Prognosis of cerebral vein and dural sinus thrombosis: results of the International Study on Cerebral Vein and Dural Sinus Thrombosis (ISCVT). Stroke 2004;35:664-70 CrossRef Medline

25. Pabinger I, Grafenhofer $H$. Thrombosis during pregnancy: risk factors, diagnosis and treatment. Pathophysiol Haemost Thromb 2002; 32:322-24 CrossRef Medline

26. James $\mathrm{AH}$, Bushnell $\mathrm{CD}$, Jamison $\mathrm{MG}$, et al. Incidence and risk factors for stroke in pregnancy and the puerperium. Obstet Gynecol 2005;106:509-16 CrossRef Medline

27. Carr ME. Diabetes mellitus: a hypercoagulable state. J Diabetes Complicat 2001;15:44-54 CrossRef Medline

28. Martinelli I, Battaglioli T, Pedotti P, et al. Hyperhomocysteinemia in cerebral vein thrombosis. Blood 2003;102:1363-66 CrossRef Medline

29. Coutinho JM, Zuurbier SM, Gaartman AE, et al. Association between anemia and cerebral venous thrombosis: case-control study. Stroke 2015;46:2735-40 CrossRef

30. Goeijenbier M, van Wissen M, van de Weg C, et al. Review: viral infections and mechanisms of thrombosis and bleeding. $J \mathrm{Med}$ Virol 2012;84:1680-96 CrossRef Medline 
31. Li K, Wohlford-Lenane C, Perlman S, et al. Middle East respiratory syndrome coronavirus causes multiple organ damage and lethal disease in mice transgenic for human dipeptidyl peptidase 4. $J$ Infect Dis 2016;213:712-22 CrossRef Medline

32. Netravathi M, Jaychandran R, Bhat M, et al. Profile of 26 HIV seropositive individuals with cerebral venous thrombosis. J Neurol Sci 2017;378:69-74 CrossRef Medline

33. Diagnosis and treatment program of novel coronavirus pneumonia (Trial Version 7). Released by National Health Commission \& State Administration of Traditional Chinese Medicine on March 3, 2020. https://www.chinadaily.com.cn/pdf/
2020/1.Clinical.Protocols.for.the.Diagnosis.and.Treatment.of.COVID19.V7.pdf. Accessed April 19, 2020

34. Yang J, Zheng Y, Gou X, et al. Prevalence of comorbidities in the novel Wuhan coronavirus (COVID-19) infection: a systematic review and meta-analysis. Int J Infect Dis 2020;94:91-95 CrossRef Medline

35. Ageno W, Becattini C, Brighton T, et al. Cardiovascular risk factors and venous thromboembolism: a meta-analysis. Circulation 2008; 117:93-102 CrossRef Medline

36. Oxley TJ, Mocco J, Majidi S, et al. Large-vessel stroke as a presenting feature of Covid-19 in the young. $N$ Engl J Med 2020;382:e60 CrossRef Medline 